\title{
EDUCAÇÃO PARA OS MEIOS NA ITÁLIA ${ }^{1}$
}

\section{Apesar de refletirem uma postura difusa em relação à comunicação/educação, os italianos demonstram um crescente interesse pelo tema}

A evolução do sistema de meios de comunicação e do sistema educacional de uma sociedade sempre ocorreu através de cruzamentos complexos e específicos entre essas duas esferas da comunicação social, com conseqüências nas práticas educativas. $\mathrm{O}$ atual estado da Educação para os Meios na Itália pode ser melhor descrito se, antes de mais nada, se percorrerem os principais pontos de transformação dessa história.

"Na Itália a história da televisão é, mais do que em nenhum outro lugar, exemplar, revestida das marcas de uma transformação social extraordinariamente rica e complexa" , portanto a televisão pode ser considerada um verdadeiro símbolo da modernidade. Quando em 1953 se fizeram as primeiras transmissões televisivas da Rádio Audizioni Italiana - RAI, a Itália era ainda um país subdesenvolvido. A maior parte da população vivia do trabalho no campo e a alfabetização de massa não tinha

\section{A AUTORA \\ Chiara Salvadori \\ Professora Doutora na Fundação Toscana \\ de Comunicação e Mídia no âmbito da \\ Universidade de Florença, Itália.}

ainda sido realizada sistematicamente. Somente dez anos mais tarde a freqüência escolar obrigatória foi elevada até a idade de 14 anos. Nessa época, quase a metade das famílias italianas já possuía um televisor, enquanto três quartos dos italianos tinham deixado de ir à escola com a idade de 10 anos ou mesmo antes ${ }^{3}$. Durante os anos do milagre econômico, a televisão teve um papel decisivo para a mudança econômica, social e cultural do país. As transmissões da RAI representaram, para a maioria da população, uma janela para o mundo ${ }^{4}$, um mundo no qual se estavam desenvolvendo rapidamente um recémnascido mercado nacional de consumo e uma rica oferta de novos modelos de ação.

Os processos de socialização foram fortemente influenciados pela televisão. Através de transmissões televisivas específicas, por exemplo, foi ensinada a língua italiana, que ainda não era falada em todo o país, e se tentou a difusão de uma alfabetização de base nas gerações mais antigas. Enquanto em outros países europeus a oralidade secundária da cultura televisiva surgiu apenas algumas décadas depois da superação da oralidade primária da cultura tra-

1. Este artigo é a tradução do italiano, que, por sua vez, vem do original escrito em alemão para a revista $J F C$ Medienconcret, Colônia, Alemanha, número monográfico dedicado à educação para os meios na Europa.

2. BECHELLONI, Giovanni. Televisione come cultura. (Televisão como cultura.) Napoli: Liguori, 1995 , p. 55.

3. GINSBORG, Paul. Storia d'Italia dal dopoguerra a oggi. (História da Itália do Pós-Guerra aos dias de hoje.) Torino: Einaudi, 1989.

4. BECHELLONI, Giovanni. Televisione.... op. cit. p. 55. 
dicional através da alfabetização de massa, na Itália esses dois processos se desenvolveram paralelamente.

A aliança do sistema escolar ainda de elite com o sistema midiático, em particular o televisivo, orientado em sentido pedagógico, era regida por interesses políticos precisos através do eterno reenvio das reformas esperadas por tanto tempo. No curso dos anos 70, porém, essa aliança foi despedaçada por movimentos sociais e culturais que, devido à velocidade da modernização italiana, até pouco tempo antes não eram previstos.

A crise paralela do monopólio estatal da televisão e da escola marcaram um passo adiante, posterior ao processo de modernização não-governada do sistema dos meios de comunicação, sistema-país ${ }^{5}$. Na metade dos anos 80 , a privatização e a descentralização da televisão abriram caminho para o nascimento do império Berlusconi e, em reação a esse desenvolvimento, a RAI sacrificou a sua função de serviço público para se adaptar ao novo contexto de concorrência.

A escola, por sua vez, ainda não se recuperou dessa crise. Foi atropelada pela concorrência da cultura da mídia que se mostra muito mais atraente às gerações jovens do que as instituições formativas tradicionais, com sua postura burocrática, elitista, o velho comportamento de seus representantes e a inadequação dos edifícios e do aparato didático.

Não se deve esquecer de que, nesta década, a crise de legitimação geral do sistema educativo italiano foi agravada pela primeira experiência difusa de desocupação intelectual (resultado da massificação da universidade).
Os professores da escola começaram a sofrer uma perda crônica de prestígio. Perda considerada uma consequiência do declínio generalizado da cultura humanística. Segundo as teorias do norte-americano J. Meyrowitz, esse nivelamento social geral pode ser considerado um efeito das mídias eletrônicas, que deixaram mais transparente o jogo dos papéis sociais.

A televisão, de fato, revela os bastidores da representação cotidiana dos diversos atores sociais a espectadores indiferenciados, que deveriam representar uma autoridade, tornando-se sempre mais difícil esconder as próprias contradições e fraquezas, e afirmar um poder indiscutível $^{6}$. Mas nisso reside, também, o potencial democratizante da televisão: de agora em diante devem ser desenvolvidos novos modelos de ação, fundados não no segredo mas na participação. No entanto, "o professor é, por sua vez, o produto de uma família, de um ciclo de formação escolar precedente, de uma formação universitária. Faz parte de um contexto e posição sociais, um local no qual aparatos e modelos culturais tiveram um peso determinante" A maior parte daqueles que exercem essa profissão ainda não parece pronta a encarar uma crise de função e de identidade.

\section{INICIATIVAS PEDAGÓGICAS NO CAMPO DA MÍDIA}

As primeiras iniciativas pedagógicas no campo da mídia foram realizadas como reação a essa desagradável experiência. Alguns professores começaram a introduzir os meios audiovisuais na didática: algumas vezes sabiam

5. SPADA, Celestino. Una modernizacione non governata. In: Confronto italiano: atti degli incontri di Cetona 1994-95. (Uma modernização não-governada. In: Confronto italiano: atas dos encontros de Cetona 1994-95.) Firenze, Regione Toscana, 1997. 6. MEYROWITZ, Joshua.Oltre il senso del luogo. (Além do sentido de lugar.) Bologna: Baskerville, 1986.

7. ABRUZZESE, Alberto. Scuola e rivoluzione cibernetica. In: Scuola democratica. (Escola e revolução cibernética. In: Escola democrática.) (Número monográfico su Scuola e Nuove Tecnologie.) Firenze: Les Monniers, 1996. p. 30. 
muito bem do potencial de inovação desses meios de comunicação; outras vezes esperavam apenas aliviar e reavivar a rotina de trabalho com essa novidade. A maior parte permanecia, entretanto, em uma posição de defesa: o cinema de autor e outras atividades da alta cultura deviam reafirmar os valores autênticos da cultura humanística européia contra a oferta da indústria cultural de massa norte-americana.

Por outro lado, essas reações espelhavam o incerto desenvolvimento das teorias e pesquisas sobre os meios de comunicação e sobre a comunicação no campo científico. Até alguns anos atrás esses temas eram considerados marginais no mundo acadêmico, com graves conseqüências para a qualidade dos estudos, em particular por causa de uma difícil integração dos estudiosos da comunicação, para os quais conflito e identidade constituíam um posterior campo minado. $\mathrm{O}$ ingresso no mundo das profissões de comunicação também acontecia sem um percurso formal específico de estudos universitários ou de algum outro tipo ${ }^{8}$. Desse modo, a divisão entre as duas mais importantes agências de reflexão social sobre a sociedade - os meios de comunicação e a pesquisa institucional - permaneceu muito profunda.

Hoje atingimos um novo ponto de transformação nesse processo evolutivo. Duas mudanças no sistema de meios contribuíram para isso: por um lado, na metade dos anos 80, o sistema televisivo italiano se transforma em um caso de estudo de fama mundial, ainda mais quando Sílvio Berlusconi começou com imprevisto sucesso a sua carreira política; por outro a crescente difusão de novas tecnologias midiáticas - no computador e nas telecomunicações -, com as suas consequiências em todos os aspectos da vida cotidiana, chamaram a atenção dos estudiosos.
Cientistas políticos, sociólogos, psicólogos e pedagogos se empenharam sempre mais nesse campo das pesquisas com o objetivo de reforçar as Ciências da Comunicação e da mídia na Itália. Em 1997, tivemos os primeiros diplomados nos cursos de graduação em Ciências da Comunicação das Universidades de Siena, Salerno e Torino. Nos anos seguintes, os diplomados serão em número cada vez maior.

Contemporaneamente multiplicam-se as ofertas de formação, por instituições públicas e privadas, preferencialmente através de financiamentos públicos, de alcance local e nacional, de curto ou longo período, com cursos desde os de alta especialização profissional às iniciativas de animação cultural para tempo livre de adultos ${ }^{9}$.

\section{FORMAÇÃO PARA O USO DE NOVAS MÍDIAS}

Nos anos 90, aconteceu uma mudança também na relação dos educadores com o sistema de meios de comunicação e emergem posicionamentos diversos com relação ao desenvolvimento das novas mídias que irão coexistir com aquelas mais tradicionais. Uma pequena minoria, irrelevante no total do contexto cultural, recusa todas as novidades em nome de um subentendido humanismo literário: a caneta não deve ser substituída por um processador de texto! No lado oposto, uma grande maioria saúda as novas tecnologias midiáticas interativas como uma salvação do declínio da cultura da televisão comercial, que teria então chegado ao fim. A estreita relação histórica entre televisão e modernização na Itália permanece dessa forma ignorada.

8. BECHELLONI, Giovanni. La scuola italiana di comunicazione. Interferenze. (A escola italiana de comunicação. Interferências.) 
Deve ser reconhecida por todos, em nome da modernização, a necessidade de uma "alfabetização" de massa das novas gerações com relação às tecnologias multimídias e de informação. Como resposta a essas exigências, o ministro da Instrução Pública, E. Berlinger, lançou o seu programa para o desenvolvimento das tecnologias didáticas (1997-2000), com base no qual professores e estudantes são formados para o uso das novas mídias.

Por outro lado, cerca de um quarto das crianças italianas tem a possibilidade de utilizar um computador em casa. Essas crianças vêm de famílias instruídas e de relativo bem-estar e freqüentemente são bastante espertas no uso do computador pessoal (PC). Mas o tempo despendido no uso do PC não é dedicado ao fim da alta cultura. A estranheza com relação a essa geração midiática cresce. Por outro lado, $75 \%$ das crianças restantes são ainda filhas da televisão. A transmissão radiofônica e televisiva tem alimentado o imaginário e a idéia que essas crianças têm da sociedade, dando forma ao seu modo de expressão ${ }^{10}$. Como podem essas crianças compreender aqueles professores que odeiam a televisão, que não a vêem e que, quando a conhecem, o fazem muito superficialmente?
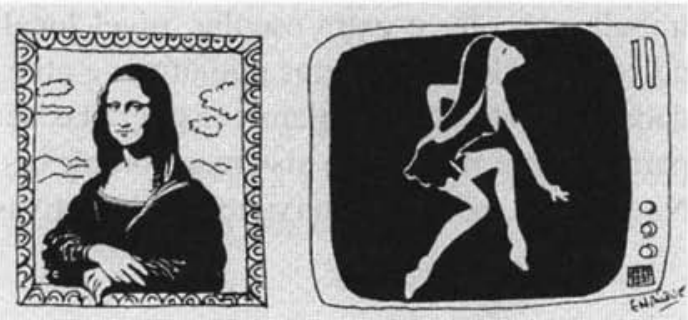

Apesar de ser reconhecido por todos o princípio de que a experiência própria das crianças e dos jovens deve ser valorizada em todos os processos formativos, a experiência cotidiana televisiva e de mercados de consumo permanecem uma exceção. As únicas intervenções realizadas nesse campo são tentativas dos pais e dos professores de reforçar o controle dessas experiências. Continuam a ser publicados livros nos quais psicólogos e pedagogos reassumem os mandamentos do bom educador com relação ao uso da televisão pelas crianças. Elas próprias aprendem essas regras muito precocemente e disso deriva uma forte contradição entre consciência e comportamento que conservarão quando adultos.

Em um contexto tão articulado não é difícil entender por que duas iniciativas diversas, com premissas teóricas que parecem bastante discutíveis, tenham suscitado muito interesse: a primeira nasceu no campo da produção de mídia; a segunda, no campo educativo. Desde fevereiro de 1998 a RAI 1 transmite um programa de informação para crianças, o TG Ragazzi, ao qual os adultos assistem mais do que as crianças, contrariando as expectativas dos produtores. Evidentemente, os adultos que trabalham nesse programa não conhecem suficientemente o mundo da infância. Por causa disso, involuntariamente, conseguem apenas reconstituir uma representação da própria imagem do que seja a infância e repropô-la a outros adultos. Uma outra vez a televisão se faz janela sobre um mundo desconhecido e dessa vez se trata do mundo infantil ${ }^{11}$. $\mathrm{O}$ segundo projeto pedagógico ${ }^{12}$ consiste em

10. BACHMAIR, Ben. Che cosa fa la televisione ai bambini? (O que faz a TV à criança?) Torino: Elle Di Ci, 1997.

11. SALVADORI, Chiara. News for children? The case of TG Ragazzi. (Notícias para crianças. O caso do TG Ragazzi.). Paper presentado al X Colloque Europeén Media and Collective Identities. Università degli Studi di Firenzi Facoltà di Scienze Politiche Cesare Alfieri. 1998.

12. O idealizador e coordenador científico do projeto é o professor Enrico Menduni, da Universidade de Estudos de Sienna. 
uma dieta televisiva, que os estudantes podem seguir em uma base voluntária: a cada transmissão vem creditado um certo número de calorias televisivas, estabelecidos por especialistas da Universidade de Sienna; a soma cotidiana dessa pontuação não deve superar o limite de 100 pontos.

Algumas iniciativas refletem uma postura difusa em relação à mídia e à cultura da infância, que na Itália é fortemente caracterizada por divisões sociais históricas e separações culturais conotadas no sentido antropológico. Todavia denotam também um crescente interesse pelos temas das culturas midiáticas entre crianças e jovens e também pelo tema da educação para os meios.

Nesse panorama estão dadas, hoje, as condições para o desenvolvimento das teorias e das práticas educativas em uma perspectiva mais ampla e sobre uma base de empenho mais forte das instituições de pesquisa e de formação.

\section{CONTRIBUIÇÕES DO MUNDO ACADÊMICO}

Do mundo acadêmico - onde os cientistas da comunicação e da mídia, pela primeira vez, há pouco tempo, consolidaram o próprio papel - vêm contribuições importantes e específicas. Bolonha, Florença, Milão, Roma, Salerno e Turim são alguns dos centros mais importantes que, de um tempo para cá, cooperam nesse campo. Além disso, há três anos, sob a orientação do professor Roberto Gianatelli (Ateneo Pontificio Salesiano,
Roma), nasceu a primeira associação italiana de educação para os meios - Media Education - MED ${ }^{13}$. O MED organiza no verão uma semana de atualização para os professores e publica um boletim de informação para os sócios. O objetivo principal da associação é o de desenvolver uma cooperação mais estreita entre as instituições que se dedicam à educação e à mídia na Itália, também para poder ampliar e reforçar, em uma perspectiva mais ampla, o diálogo no plano internacional.

Nesse contexto, as atividades ligadas ao Curso em Comunicação e Mídia da Faculdade de Ciências Políticas da Universidade de Florença têm um papel decisivo. Junto a essa faculdade, vêm se desenvolvendo há dez anos projetos de pesquisa e formação sobre o tema da educação para os meios, relacionada com a rede européia Sócrates/ Erasmus. Todos os projetos se baseiam no princípio fundamental da integração da multiplicidade de experiências diversas, que hoje é mais possível do que nunca e deve ser considerada o fator propulsor de qualquer projeto de formação.

É importante que teoria e prática, tecnologia e cultura, ensinamento e aprendizado, trabalho escolar e extra-escolar, nível local, nacional e global ${ }^{14}$, ofertas midiáticas e atividades educativas não sejam consideradas separadamente mas como sistemas complexos. $\mathrm{Na}$ prática, todas as intervenções formativas

13. As teorias de Len Mastermann são uma importante fonte de inspiração para o trabalho desse grupo. Ver: GIANNATELLI, Roberto, RIVOLTELLA, Piercesare. Teleduchiamo, linee per un uso didattico della televisione. (Teleeducamos, linhas para um uso didático da televisão.). Torino: Elle $\mathrm{Di} \mathrm{Ci}, 1994$.

14. A esse respeito podem-se observar que existem sempre mais escolas com site próprio na Internet, sobretudo em regiões como Emilia Romana, Toscana e Veneto. Ver: Cataldi, Internet a scuola. Un tuffo nella rete. (Internet na escola. Um mergulho na rede.) In: ABRUZZESE, Alberto. Scuola democratica. op. cit. p. 131. Outras informações podem ser encontradas no site da Biblioteca Nacional Pedagógica de Florença (http://www.bdpd.fi.it). 
têm o objetivo principal de melhorar a comunicação entre os grupos e entre as gerações. Isso é possível através de um trabalho comum sobre as respectivas culturas midiáticas - sejam aquelas clássicas ou aquelas ligadas ao mercado de consumo ${ }^{15}$. Na Itália, isso significa, ainda, na maior parte dos casos, confrontar-se sobre as respectivas experiências televisivas. Nos dias 10 e 11 de junho de 1998, a Giornate
Fiorentine della Comunicazzione (Jornadas Fiorentinas de Comunicação), um evento internacional que se realiza todo ano por ocasião da entrega dos diplomas do Curso, foi dedicada pela segunda vez ao tema Children and Television - A New Programme for Media Education (Criança e Televisão. Um Novo Programa para a Educação para os Meios). E o diálogo continua.
Resumo: A autora faz um traçado histórico em que mostra como os meios de comunicação, em particular a televisão, se imbricam no cotidiano da Itália. Discute a resistência da cultura humanística européia à oferta da indústria cultural de massa e enumera os principais fatores que deram aos meios de comunicação um lugar proeminente na formação de uma cultura de mídia. Destaca, diante da evidente importância de a escola preocupar-se com a formação de estudantes e de professores com o uso das novas mídias, as iniciativas para o desenvolvimento do campo da comunicação/educação, cujo princípio fundamental é a integração da multiplicidade de experiências diversas, fator propulsor de qualquer projeto de formação.

Palavras-chave: Itália, televisão, comunicação/educação, escola, formação de comunicadores
Abstract: The author elaborates a historical tracing in which she shows how the means of communication, in particular television, overlapped each other in the Italian day-to-day life. She discusses the resistance the European humanistic culture has to the offer of the mass cultural industry and lists the main factors that gave the media a prominent place in forming a media culture. She stresses, considering the evident importance of the school concerning itself with forming students and teachers on using the new media, the initiatives to develop the communication/education field that has as their fundamental principle integrating the multiplicity of experiences, a factor that propels any background-forming project.

Key words: Italy, television, communication/ education, school, communicator education

15. Por exemplo, vem sendo constituído em uma classe um grupo de pesquisa sobre comportamento de fruição televisiva de amigos e/ou familiares. Esse grupo trabalha sobre uma base de entrevistas, observações, análises de programas e discussões comuns sobre resultados. Em outro projeto, os estudantes elaboram, em grupo, uma história escrita, de própria autoria, com a única condição de conter ao menos uma personagem pertinente ao imaginário da mídia e ao menos uma personagem retirada da própria "realidade" cotidiana. O conjunto dos projetos realizados do grupo ativo junto com o Curso de Florença foi reunido sob a denominação Pandora. Un progetto di educazione intergenerazionale. (Pandora. Um projeto de educação inter-gerações.), cujos primeiros resultados em elaboração serão discutidos em Florença. 